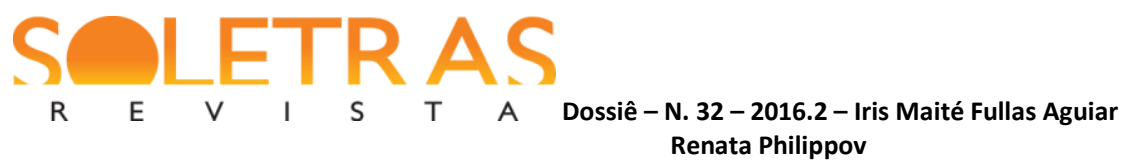

\title{
A herança do heroico e do trágico nos videogames e uma breve análise do jogo eletrônico The Last of $U$ s
}

\author{
Iris Maité Fullas Aguiar ${ }^{1}$ \\ Renata Philippov ${ }^{2}$ \\ Universidade Federal de São Paulo
}

Resumo: Considerando as transformações sociais, em especial no que se refere ao desenvolvimento de novas mídias, que apresentam grande potencial narrativo, este artigo apresenta como objetivo propor uma reflexão acerca da relação entre as novas mídias, em especial o videogame, e a Literatura. Além disso, o artigo ressalta o caráter intertextual das mídias, que muitas vezes exploram narrativas já conhecidas do grande público, através de suas reconfigurações. Observando as questões supracitadas, é possível observar que os temas explorados nos jogos eletrônicos apresentam uma estreita ligação com os textos clássicos, mais especificamente a epopeia e a tragédia. Além de apresentarem temas recorrentes, tanto os textos clássicos como os jogos eletrônicos abrigam similaridades em sua estrutura. $\mathrm{O}$ artigo também se propõe a analisar o jogo eletrônico The Last of Us a fim de evidenciar os elementos em comum entre as epopeias e as tragédias clássicas e o jogo em questão, em especial no que se refere à relevância do papel do herói para o desenvolvimento dessas narrativas.

Palavras-chave: Literatura. Videogame. Intertextualidade. Epopeia e tragédia. The Last of Us.

\footnotetext{
${ }^{1}$ Trabalha como docente de Língua e Literatura Inglesa há mais de quinze anos. Atualmente faz parte do corpo docente da Associação Cultura Inglesa e da Faculdade Sumaré. Possui licenciatura em Português e Inglês pelo Centro Universitário Sant'anna, título de especialista em Língua Inglesa pela Universidade São Judas Tadeu e atualmente é discente do Programa de Mestrado em Letras da Universidade Federal de São Paulo.

${ }^{2}$ Doutora em Letras pela Universidade de São Paulo (2004), pós-doutora em Linguística Aplicada pela Pontificia Universidade Católica de São Paulo (2015) e pós-doutoranda em Teoria Literária e Literatura Comparada pela Universidade de São Paulo. É docente de Língua Inglesa e Literaturas de Língua Inglesa junto ao Departamento de Letras da Universidade Federal de São Paulo e credenciada no Programa de Mestrado em Letras na mesma instituição.
} 


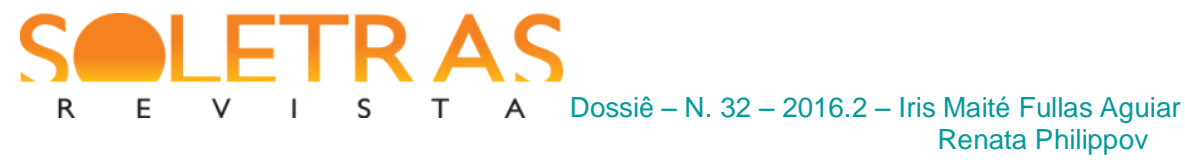

\section{Introdução: Videogame e Literatura: uma relação intertextual}

Narrativas têm participado ativamente das práticas sociais e das operações da imaginação humana desde os tempos mais remotos, sendo manipuladas e recontadas com o uso de diferentes recursos, tais como: fala, representação visual e o uso da escrita. Considerando as transformações sociais e o surgimento de novas mídias, o processo de narrar histórias tem se revelado uma fonte produtiva de estudo e admiração. Dentre essas mudanças, uma plataforma que tem adquirido grande visibilidade e se tornado alvo de estudos é o videogame, uma vez que os jogos eletrônicos são como uma plataforma com grande potencial narrativo a ser explorado e, a nosso ver, melhor compreendido.

Mesmo com a crescente popularidade dos jogos eletrônicos na sociedade atual e com o reconhecimento de seu potencial narrativo, os videogames ainda são alvo de muitas críticas e questionamentos, na medida em que são acusados de fomentar a violência entre os seus praticantes e de não serem dignos de habitar o hall das artes. No entanto, analisando a estrutura da narrativa de um certo gênero de jogos, especialmente de $R P G^{3}, S_{a n d b o x^{4}}$ e de aventura, é possível encontrar padrões recorrentes de estruturação presentes não somente nos textos literários, mas também no cinema, nos quadrinhos ou em qualquer plataforma que tenha o potencial de desenvolver uma narrativa, sendo ela linear ou não.

A combinação de Literatura e videogame pode parecer improvável e pouco convencional. No entanto, se considerarmos as modificações sociais e a forte presença da interatividade na sociedade contemporânea, tal combinação torna-se não somente possível, mas quase inevitável. Lefévere considera que a literatura:

poderia ser compreendida como espaço em que elementos complexos se interrelacionam, compartilhando certas características e, ao mesmo tempo, definindo-se com base em diferenças que são construídas institucionalmente. A literatura seria constituída tanto de textos quanto de seres humanos que efetuam leituras, escrituras e reescrituras numa determinada cultura, articulando e produzindo saberes que possibilitam sua manifestação como um produto cultural. (LEFÉVERE, 1992 apud AMORIM, 2005, p. 27).

\footnotetext{
${ }^{3}$ Role-Playing games ou jogos de interpretação de papéis: os jogadores assumem o papel de diferentes personagens e criam narrativas colaborativamente.

${ }^{4}$ Termo utilizado para se referir aos jogos onde não há barreiras para o jogador, sendo este livre para fazer escolhas e seguir o caminho que desejar durante o jogo, o que torna a experiência de cada jogador única.
} 
Isso posto, a existência da Literatura estaria intimamente ligada a fatores sociais que influenciariam a sua constituição e, por consequência, as expressões artísticas ligadas a ela. Assim, Literatura e sociedade caminhariam juntas, sendo a primeira o resultado das transformações da segunda e, de certa forma, sendo a segunda influenciada pela primeira. Desse modo, considerando o videogame como uma mídia que reflete as mudanças sociais, fica estabelecida, portanto, a naturalidade com que o videogame passaria a ser uma plataforma para a manifestação da Literatura, através de narrativas já conhecidas ou não, proporcionando a interatividade que a sociedade atual demanda.

Mesmo diante da sensação de que as novas mídias estão muito distantes dos textos clássicos, de sua estrutura e de seus temas, é possível encontrar alguma correlação entre elas. Um exame mais cuidadoso revela que a literatura está mais próxima dos jogos eletrônicos do que possa parecer, e que há uma forte ligação intertextual entre os dois gêneros. Tomando a observação de Samoyault (2008, p.10) acerca da intertextualidade: "O que é ela, com efeito, senão a memória que a Literatura tem de si mesma? " e aplicando tal afirmação aos jogos eletrônicos, podemos notar que, em certa medida, esses jogos participam da memória da Literatura, resgatando estruturas narrativas clássicas, personagens, temas e motivos familiares a ela. Hutcheon ressalta que as histórias serão eventualmente recontadas:

As histórias são, de fato, recontadas de diferentes maneiras, através de novos materiais e em diversos espaços culturais; assim como os genes, elas se adaptam aos novos meios em virtude da mutação - por meio de suas "crias" ou adaptações. E as mais aptas fazem mais do que sobreviver; elas florescem. (HUTCHEON, 2011, p.59)

As adaptações de narrativas já conhecidas para videogame tem aumentado consideravelmente, tanto as oriundas de filmes quanto as de livros. Podemos entender esse movimento como parte do processo evolutivo das narrativas; como "crias" delas mesmas. Esse processo de mutação, de uma certa maneira, faz parte das modificações humanas e sociais. Isso posto, a mutação passa a ser quase inevitável. Dessa maneira, Hutcheon (2011) aponta que: 

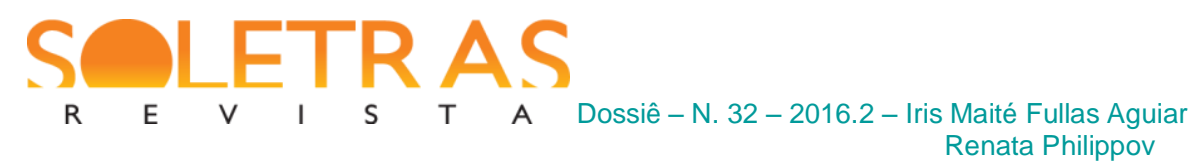

As histórias não são imutáveis; ao contrário, elas também evoluem por meio da adaptação ao longo dos anos. Em alguns casos, tal como ocorre na adaptação biológica, a adaptação cultural conduz a uma migração para condições mais favoráveis: as histórias viajam para diferentes culturas e mídias. Em resumo, as histórias tanto se adaptam quanto são adaptadas. (p.58)

É como se as histórias tivessem uma vida independente da plataforma onde foram concebidas e fossem dotadas da capacidade de se moldarem às diferentes culturas e plataformas que estivessem dispostas a recebê-las. Essa relação pode ser definida como hipertextualidade, conceito cunhado por Genette (1966) e o qual Samoyault (2008, p. 29) define como: “a relação pela qual um texto pode derivar de outro anterior". Destarte, esse conceito torna possível o estudo da relação entre os textos já existentes e as novas narrativas apresentadas nos jogos para videogame.

Quando as histórias viajam de uma cultura para outra ou de uma mídia para outra, passam por um processo de reescritura, tendo seus componentes narrativos modificados para se adaptarem aos moldes da nova mídia. Quando as narrativas migram para o videogame, as descrições dos locais são transformadas em cenários, as informações sobre as personagens são mostradas e não contadas, as emoções são vivenciadas pelos leitores através da interação com os objetos dispostos ao longo das fases e dos obstáculos enfrentados pelo jogador além de apresentarem a possibilidade de o leitor se colocar no papel do personagem, resultando, assim, em uma experiência narrativa singular. Cabe ao jogador, assim como ao leitor, explorar os elementos que estão ali apresentados para desvendar os detalhes da narrativa com a qual ele está interagindo.

Assim como observado por Hutcheon (2011), a migração das narrativas para essa nova plataforma que é o videogame pode colaborar para a evolução das histórias, criando novas possibilidades para suas personagens dentro de um universo já estabelecido. Nesse âmbito, Spalding aponta que:

(...) videogames provaram o seu valor em muitas vias, mais especificamente em sua habilidade de criar novas narrativas. Muitos jogos são baseados diretamente em fontes de material literário e, nesse âmbito, trazem novas 
histórias para personagens queridos. (SPALDING, 2012, loc. 699. Trad. nossa) ${ }^{5}$

A incrível capacidade que o vídeo game oferece de não somente proporcionar uma experiência interativa única entre o leitor e suas personagens preferidas, mas também de oferecer diferentes narrativas a partir daquelas já conhecidas pelo público merece, a nosso ver, ao menos uma investigação mais cuidadosa. Essa relação já se mostrou muito frutífera para ambas as plataformas, já que tanto os livros quanto os jogos testemunharam os desdobramentos de suas narrativas. É o caso do jogo Assassin's Creed, lançado em 2007 e desenvolvido e distribuído pelas empresas Ubisoft e Gameloft, jogo que ganhou uma coleção de oito livros lançados entre 2009 e 2015. Os livros não seguem necessariamente a mesma série de eventos apresentados no videogame, na medida em que exploram o universo dos jogos e acompanham a jornada de alguns personagens.

A relação entre texto, imagem e interação está cada vez mais estreita, possibilitando ao leitor explorar diversos canais da história e viver diferentes experiências na interação com cada uma das mídias através das quais ele estabelece contato com a história. As opções ficam cada vez mais numerosas e a exploração dos componentes narrativos de uma história se multiplicam proporcionando experiências únicas para os leitores e, assim, colaborando para a perpetuação da obra.

No exame das narrativas adaptadas, é importante ressaltar que cada mídia é única, assim como o são suas especificidades e a experiência interativa que ela oferece ao leitor/expectador. Uma plataforma não pode ser julgada com base nos mesmos parâmetros que as outras, conforme Carvalhal ressalta:

nada pode alterar a natureza de um dos elementos relacionados. Assim, o poema não se converte em sinfonia por sua simples designação como tal, continua a ser um poema, com uma estrutura que lhe é própria e jamais será exatamente a mesma da outra arte. (CARVALHAL, 1991, p.14)

Vale lembrar que os desenvolvedores de videogame não são os primeiros a aproveitar narrativas já existentes para a criação de seus jogos. Desde a antiguidade, a prática

\footnotetext{
${ }^{5}$ Video games have proven their worth in many avenues, but specifically in their ability to create new narratives. Many video games are based directly off of a literary source material, and within these bring new stories for many beloved characters. (SPALDING, 2012, loc. 699)
} 
de retomar histórias já conhecidas do grande público era comum, pois a originalidade estava no tratamento dado aos textos e não necessariamente em contar uma narrativa totalmente nova.

Provavelmente o mais conhecido integrante desse grupo de "adaptadores" de narrativas seja William Shakespeare. Não é estranho aos estudiosos e entusiastas de sua obra o fato de que suas peças eram reescrituras de histórias já há muito conhecidas do grande público. De acordo com Mangan (2013, p. 281), estudioso da obra shakespeariana, dentre tantos outros, o bardo adaptava para os palcos narrativas que migravam de outros tempos e até mesmo de outras culturas.

\section{A presença da tragédia e da epopeia no jogo The Last of Us: similaridades estruturais}

Suckling \& Walton reconhecem que não necessariamente um jogo tenha que apresentar uma narrativa. No entanto, os autores ressaltam a importância da existência de um tema ou de uma história para que o jogo seja bem-sucedido:

Em outro sentido, poderíamos dizer que jogos não necessariamente precisam de enredos, mas sem temas pode ser que eles não consigam engajar uma audiência de uma maneira sólida. Tente imaginar Space Invaders sem um tema, tente imaginar um jogo do Tomb Raider sem Lara Croft, e sem um tema ou um mundo imaginário para nenhuma de suas ações. Jogos são geralmente mais atraentes quando eles sucumbem a nossa necessidade por histórias. (SUCKLING \& WALTON, 2012, loc. 4286. Trad. nossa) ${ }^{6}$

Mesmo estando frente a uma nova plataforma, a relevância das narrativas para o público é extremamente pertinente. Mesmo com as mudanças na sociedade e com os avanços tecnológicos, a forte relação da sociedade com as histórias e o poder que estas exercem sobre os expectadores permanece.

Uma análise dos textos clássicos (epopeias e tragédias) e os jogos de videogame revela que há uma ligação estreita na maneira de estruturação da narrativa. Tanto nos primeiros quanto nos últimos, é necessário que inicialmente seja feita uma ambientação da

\footnotetext{
6 In another sense, we might say that games may not necessarily need plots, but without themes may fail to engage with an audience in any enduring way. Try imagining Space Invaders without the theme, Try imagining a Tomb Raider game without Lara Croft, and without a theme or story-world context for any of your actions. Games are generally more compelling when they succumb to our need for stories. (SUCKLING \& WALTON, 2012, loc. 4286)
} 
história que representa o princípio do movimento da ação, para que então os eventos se compliquem e os obstáculos sejam apresentados para que finalmente seja alcançada a soltura ou o desenlace, em que o herói finalmente alcança o objetivo estabelecido no início da narrativa.

Nos textos clássicos, é nesse ponto que, por exemplo, Édipo Rei sofre a pena que ele mesmo tinha estabelecido para o assassino do Rei e que Enéias colabora para a expansão do Império Romano e a fundação da cidade que depois daria origem a Roma. Nos jogos eletrônicos é nesse ponto que o herói Mario, nos jogos do Super Mario, salva a princesa Peach, que no jogo Shadow of Mordor, baseado no livro The Lord of the Rings, o personagem Talion mata a forma física de Sauron e que Joel, o herói de The Last of Us, salva Ellie, a menina por ele protegida, de ser morta pelos pesquisadores no hospital para o qual ele a estava levando.

A sequência das ações é primordial para que o desenlace ou a soltura da obra atinja o efeito esperado no leitor ou, no caso dos jogos, o jogador, pois então os personagens alcançarão a solução para seus conflitos, sejam eles positivos ou não. Nas palavras de Aristóteles:

Dando uma definição mais simples, podemos dizer que o limite suficiente de uma Tragédia é o que permite que nas ações uma após outra sucedidas, conformemente à verossimilhança e à necessidade, se dê o transe da infelicidade à felicidade ou da felicidade à infelicidade. (ARISTÓTELES, circa 335 a.C./1992, p.49)

É nesse sentido que é primordial que a composição da narrativa, ou do que Aristóteles chama de Mito, seja cuidadosamente organizada, pois nas palavras do autor: "É necessário, portanto que os Mitos bem compostos não comecem nem terminem ao acaso, mas que se conformem aos mencionados princípios" (p.47). Assim, todos os eventos que fazem parte da trama da narrativa devem estar interligados e compor uns aos outros, para então constituírem a unidade da narrativa. Nas palavras de Aristóteles (1992):

(...) o elemento mais importante é a trama dos fatos, pois a Tragédia não é imitação de homens, mas de ações e de vida, de felicidade [e infelicidade; mas felicidade] ou infelicidade, reside na ação, e a própria finalidade da vida 
Renata Philippov

é uma ação, não uma qualidade. (...) não agem as personagens para imitar caracteres, mas assumem caracteres para efetuar certas ações; por isso as ações e o Mito constituem a finalidade da Tragédia, e a finalidade é de tudo o que mais importa. (p. 41)

Assim, as personagens assumiriam o papel de praticar ações que formam os fios que dão forma ao tecido da trama, pois é a combinação dessas ações que vai garantir a unidade de sentido do todo. São as ações das personagens em The Last of Us que garantem que o jogador experimente diferentes emoções e explore os conflitos apresentados ao longo da narrativa. Eis alguns exemplos de momentos de conflito do jogo: a morte da filha de Joel, os confrontos com os infectados, as fugas dos não infectados, a descoberta por parte de Joel de que Ellie vai morrer e o momento em que ele fica ferido e impossibilitado de protegê-la. São esses eventos que compõem e desenvolvem a trama, formando uma composição única.

Ao examinarmos as palavras de Almeida acerca da organização da epopeia, também podemos encontrar semelhanças entre os jogos e as narrativas clássicas:

Consta a epopeia d'alma e de corpo: a alma é a imitação que por nostalgia se chama fábula. Este nome fábula inclui em si e com uma mesma razão ao que chamamos argumento, hipótese, episódios e a ligadura de um e de outros. Argumento é a história sobre que funda o poema; esta, ou há de ser verdadeira, ou fábula, ou ficção nova verossímil. (ALMEIDA, 2006, p. 3)

Novamente nos é apresentada uma estrutura muito próxima entre a utilizada nos textos clássicos e a presente no desenvolvimento dos jogos eletrônicos. Em The Last of Us, além de nos ser apresentada a sequência da narrativa já supracitada (apresentação, desenvolvimento e desenlace), temos a separação da narrativa em quatro capítulos principais, demarcados pelas quatro estações do ano. Cada capítulo oferece um objetivo maior que sofre influência direta da estação em que está inserido. Quando o jogador alcança o inverno, ele sabe que irá enfrentar maior dificuldade do que quando está no verão ou na primavera; nesse sentido, as ações praticadas e sofridas pelo jogador mimetizam as características das diferentes estações do ano.

Além disso, temos aqui colocada a relevância das narrativas para a sociedade. Mesmo com as mudanças e os avanços tecnológicos, a forte relação com as histórias e o poder 
que elas exercem sobre os expectadores permanece. Com base nas ideias de Aristóteles (1992), Chatman, Barthes e Field, Suckling e Walton (2012) apresentam-se três princípios que, de maneira geral, resumem as ideias dos quatro autores acima e definem a estrutura da trama da narrativa:

1. Um enredo deve ter uma unidade e uma forma básica, desenvolvendo-se ao longo de um caminho "lógico" e linear até alcançar seu desfecho (dénouement) definitivo.

2. De sua rota até seu desfecho (dénouement), um enredo requer "momentos" ou “eventos” chave e "incidentes” fundamentalmente responsáveis por engajar o público.

3. Um enredo requer outros elementos em conjunto, tais como personagens, ambientação e atmosfera, os quais não estão diretamente ligados à causalidade linear dos "eventos" ou “incidentes", mas ainda assim são essenciais. (SUCKLING \& WALTON, 2012, loc. 4616. Trad. nossa) ${ }^{7}$

Considerando esses três princípios, é fundamental observar a relevância do terceiro para os jogos eletrônicos. As personagens, o ambiente e a atmosfera do jogo são os elementos responsáveis não somente pelo impacto visual do jogo, mas, acima de tudo, são eles que asseguram o desenvolvimento da ação (ou das ações) que são as responsáveis por manter a unidade de sentido da trama.

Nesse aspecto, o jogo apresenta um herói envolto em um grande conflito, através da relação mimética com a personagem Ellie, que funciona como um tipo de substituta para a sua filha, morta no início do jogo. O ambiente do jogo não somente mostra o grau de destruição do mundo, mas também a exuberância da natureza que já tomou conta dos destroços criando um clima de nostalgia para Joel e de admiração para Ellie, pois ambos são obrigados a viver escondidos, longe de espaços abertos onde estariam vulneráveis aos ataques dos infectados e dos não infectados. Portanto, assim como nos textos impressos, temos as

7 1. A plot should have unit and basic form, developing along a linear and "logical" path to ultimate denouement.

2. En-route to denouement, a plot requires key "moments", "events" or "incidents" in time fundamentally responsible for engaging the audience.

3. Plot requires other elements in conjunction, such as characters, setting, and atmosphere, which are not directly tied to the linear causality of the "events" or "incidents", but are still essential. (SUCKLING \& WALTON, 2012, loc. 4616) 
descrições dos ambientes e muitas vezes somos arrebatados pela beleza e pela força das palavras, na medida em que nos jogos somos profundamente impactados pela beleza e pelos detalhes dos cenários, o que colabora para uma intensa experiência entre nós, enquanto jogadores, e a narrativa.

\section{O herói em The Last of Us: um herói clássico num mundo moderno?}

A sobrevivência das histórias através das novas mídias e a possibilidade de elas florescerem só reforçam a forte conexão entre as histórias e os jogos eletrônicos, fazendo com que eles se tornem fortes aliados da Literatura e de seu florescimento. Tal característica é ainda mais significativa quando nos é apresentada uma narrativa que gira em torno de um herói que é colocado frente a uma situação extrema e deve superá-la ao longo de sua jornada.

É possível observar tal característica desde em jogos mais rudimentares, sem mudança de cenário e sem interação com outros personagens até nos jogos mais elaborados, onde há mudança de cenário, interação com outros personagens e até mesmo a possibilidade de interação do jogador com o desenvolvimento da narrativa.

Como exemplo de jogo mais rudimentar, podemos citar Donkey Kong, lançado pela Nintendo em 1981. Nele, o conhecido personagem Mario Bros, na época conhecido como Jumpman, tem como objetivo resgatar a princesa no canto superior esquerdo da tela, tendo que escapar dos tambores lançados por Donkey Kong. Não há mudança de cenário, nem mesmo interação com outros personagens; no entanto, já está plantado aí o início do que seria então uma franquia de jogos de grande sucesso até os dias de hoje, o desenvolvimento de inúmeros jogos, todos motivados pelo resgate da princesa pelo personagem Mario. Vale ressaltar que os jogos da franquia desenvolvidos atualmente apresentam maior elaboração da narrativa e de cenário e a possibilidade de se interagir com um número considerável de personagens que passaram a habitar o universo do conhecido herói Mario, que deve resgatar a Princesa Peach.

Considerando os jogos mais elaborados, é possível citar Heavy Rain, desenvolvido pela empresa Quantic Dreame lançado em 2012 pela Sony Computer Entertainment. Nesse jogo, é possível modificar o curso e o desfecho da narrativa de acordo com as ações do jogador e até mesmo acessar os pensamentos dos personagens, estabelecendo um diálogo interno sobre a narrativa e o contexto em que estão inseridos. 
Os jogos eletrônicos cada vez mais tem provado ser uma plataforma com grande potencial narrativo, assim como os textos escritos, o cinema e o teatro, não somente por apresentarem elementos similares aos presentes em qualquer narrativa (personagens, ambientação, clímax e desenlace), mas também por explorarem desafios. Segundo Ryan (2004, p.349 apud HUTCHEON, 2011, p. 36): "o segredo para o sucesso narrativo dos jogos é sua habilidade de explorar uma das forças mais fundamentais que movem um enredo adiante: a resolução de problemas". De fato, o que move o amor pelas narrativas é a possibilidade de alcançar um desfecho para um conflito que nos é apresentado.

No jogo The Last of Us, o herói Joel é colocado em um mundo pós-apocalíptico onde as pessoas foram infectadas por um fungo mutante que as transformou em monstros canibais, contexto relativamente recorrente nos videogames; entretanto; há um elemento complicador da narrativa, que é a morte da filha de Joel logo no início do jogo. Tal evento é primordial para a consolidação da relação entre o herói e Ellie, a adolescente que ele terá que proteger durante o jogo, e que representa uma possível cura para o fungo mutante que destruiu o mundo assim como o conhecemos. A relação entre Joel e Ellie replica a relação do personagem com sua filha no início da narrativa e é crucial para o desenvolvimento da tensão na trama em vários momentos, nos quais Ellie deve ser protegida não somente dos humanos infectados, mas também dos humanos não infectados que tentam impedir a chegada dos dois ao hospital, onde uma possível vacina para a cura está sendo desenvolvida.

Tendo tais colocações em mente, é possível observar que os jogos que seguem essa estrutura apresentam uma forte ligação com os modelos clássicos literários, que refletem a figura de um herói que busca um bem maior, que tem as suas ações de certa forma predestinadas e que as aceita por compreender que são permeadas pela busca de um bem comum. Quando nos referimos à figura do herói clássico, estamos nos referindo ao sujeito que é parte do que Lukács chama de era das "culturas fechadas":

Essa é a era da epopeia. Não é a falta de sofrimento ou a segurança do ser que revestem aqui homens e ações em contornos jovialmente rígidos (o absurdo e a desolação das vicissitudes do mundo não aumentaram desde o início dos tempos, apenas os cantos de consolação ressoam mais claros ou mais abafados), mas sim a adequação das ações às exigências intrínsecas da alma: à grandeza, ao desdobramento, à plenitude. Quando a alma ainda não conhece em si nenhum abismo que a possa atrair à queda ou a impelir a alturas ínvias, quando a divindade que preside o mundo e distribui as dádivas desconhecidas e injustas do destino (...) (LUKÁCS, 2000, p.25) 
Essa figura do herói clássico reflete, portanto, um ser que agirá sempre dentro de um ambiente de certezas e de plenitude. Isso posto, é oportuno que se tenha ao menos um olhar curioso para essa relação entre os modelos clássicos e as novas mídias, a fim de compreendermos em que medida os jogos eletrônicos refletem tais modelos clássicos. Estaríamos frente a um novo modelo híbrido em que o videogame representaria um novo caminho para uma definição estrutural do fluxo narrativo?

O jogador, assim como o leitor, não interage com a obra passivamente. Ele faz elaborações frente às escolhas e às atitudes do herói. Ele se vê forçado a tomar algumas atitudes, assim como o leitor deve aceitar aquelas tomadas pelo personagem. No entanto, ambos as questionam gerando um conflito entre o individual e o coletivo. Esse conflito é essencial para a narrativa, pois é ele que vai atribuir sentido a ela. No caso de Joel, esse conflito está presente no momento em que chega ao hospital onde os testes para a vacina estão sendo desenvolvidos e descobre que Ellie será morta para que a pesquisa seja realizada. Ele, então, decide tirar a adolescente anestesiada do hospital e mata algumas das pessoas presentes. Quando ela acorda da anestesia, ele mente dizendo que os cientistas tinham encontrado outras pessoas que, assim como ela, eram imunes ao fungo, mas que não tinham obtido êxito no desenvolvimento de uma vacina e que, portanto, não precisavam mais dela.

Esse conflito é indispensável para a verossimilhança da composição da narrativa que permeia não somente os textos literários clássicos, mas também os jogos eletrônicos, pois eles se sustentam muitas vezes na imitação de ações possíveis, pois é esta a responsável por provocar no leitor ou no jogador o sentimento desejado pelo escritor. Nas palavras de Aristóteles (op.cit, p. 67): “Como a composição das Tragédias mais belas não é simples, mais complexa, e, além disso, deve imitar casos que suscitam o terror e a piedade (porque tal é o próprio fim desta imitação)".

Através desse recurso é que se alcançará o efeito desejado e será possível o desenvolvimento de uma narrativa consistente. Outra forte semelhança entre os videogames e os textos clássicos é a organização estrutural em que são apresentados. Almeida (2006), quando fala da alma da epopeia, apresenta a seguinte definição de estruturação:

Em quatro partes se divide a fábula conforme os afetos que move. A primeira se chama prótasis, porque é um princípio do movimento da ação. A segunda tárasis, porque o movimento vai crescendo e turbando-se. A 
Renata Philippov

terceira catástasis, em qual a turbação está no cume: a esta terceira parte se dizem nó; a quarta catástrofe, e é o mesmo que soltura. (ALMEIDA, op.cit, p.6)

Observemos como a definição apresentada por Suckling \& Walton se assemelha àquela apresentada por Almeida:

No estágio inicial de uma história, ela é geralmente dividida em três ou cinco atos que dão uma estrutura bruta ao jogo com um início, um meio e um fim. O primeiro ato (as vezes chamado de setup) é usado para introduzir a premissa dramática, personagens que habitam aquele mundo, e eventos que conduzirão a história. O segundo ato é onde o herói deve enfrentar e superar uma série de obstáculos para alcançar o seu objetivo. O terceiro e último ato envolve resolução, onde você decide como as coisas terminam. (SUCKLING \& WALTON, op.cit, loc. 2105. Trad. nossa) ${ }^{8}$

Além disso, os incidentes que compõem a obra são apresentados ao jogador de maneira engenhosa, fazendo com que Joel passe por momentos de grande dificuldade e perigo para então alcançar o que seria o seu destino como herói, entregando Ellie para os pesquisadores e alimentando a possibilidade de salvação para a humanidade. No entanto, nosso herói está prestes a enfrentar o pior momento de sua jornada, pois ele terá que presenciar, de mãos atadas, novamente a morte de sua "filha". O evento maior buscado ao longo do jogo, que é a possível salvação da humanidade e que representaria o desenlace da trama, na verdade acaba sendo o contrário do esperado. Tal evento de contrariedade em relação às expectativas do público não é estranho aos textos clássicos; muito pelo contrário, ele já podia ser observado na Eneida e em Édipo Rei, sendo assim o que Almeida (2006) define como peripécia:

uma mudança súbita de coisa em contrário estado do que antes era, como Enéias vencido e foragido em Tróia, vencedor e glorioso em Itália. Há dois

\footnotetext{
${ }^{8}$ At the outline stage it initially breaks a story into usually three or five acts giving a rough structure of a beginning, middle, and end to the game. The first act (sometimes called setup) is used to introduce the dramatic premise, world characters, and events that will drive the story forward. The second act is where the hero must face and overcome a series of obstacles in order to reach their goal. The third and final act involves resolution where you decide how things end. (SUCKLING \& WALTON, op.cit, loc. 2105)
} 
modos de peripécias: uma, que passa de mal a bem, como esta de Enéias; outra de bem a mal, como Dido e Turno. (ALMEIDA, op.cit, p. 4)

Aristóteles (op.cit, p.61) define peripécia como: "a mutação dos sucessos no contrário" e diz que "esta inversão deve produzir-se (...) verossímil e necessariamente". É exatamente isso que nos é apresentado no jogo, justamente no momento em que o jogador acredita ter completado a sua busca e cumprido o seu papel, descobrimos a questão da morte da adolescente. Nesse momento, nosso herói, cheio de certezas quanto ao seu papel, encara um conflito de ordem individual e decide então salvar Ellie, rejeitando a posição de herói que aceita o desfecho inevitável para o bem comum, nesse caso, a salvação da humanidade.

Talvez nesse aspecto o herói de The Last of Us falhe como herói clássico e se comporte mais como um herói romanesco, pois se vê em uma sociedade fragmentada onde não há mais unidade, diferente dos tempos vividos por Enéias e Édipo. De uma certa maneira, temos um herói moderno vivendo conflitos clássicos, que tem que lidar com interesses individuais ao mesmo tempo em que tenta atender ao bem comum. Nesse sentido, Lukács (2000) diferencia o herói romanesco do da epopeia:

O herói da epopeia nunca é, a rigor, um indivíduo. Desde sempre considerou-se traço essencial da epopeia que seu objeto não é um destino pessoal, mas o de uma comunidade. E com razão, pois a perfeição e completude do sistema de valores que determina o cosmos épico cria um todo demasiado orgânico para que uma de suas partes possa tornar-se tão isolada em si mesma, a ponto de descobrir-se como interioridade, a ponto de tornar-se individualidade. A onipotência da ética, que põe cada alma como única e incomparável, permanece alheia e afastada desse mundo. (op.cit.,p.67)

O herói de The Last of Us está inserido em um mundo onde não há certezas, muito menos completude do sistema de valores. Os integrantes de sua sociedade não mais trabalham para o bem comum, como parte de um todo orgânico, mas sim partindo de questões individuais e isoladas, na tentativa de reorganizarem essa sociedade fragmentada e incerta. $\mathrm{O}$ herói do jogo, assim como o romanesco, quebra as convenções em busca de se reencontrar e conhecer a si mesmo em um mundo onde não há mais certezas, o que Lukács (2000) afirma ser fruto da insegurança do mundo moderno: “A segurança interior do mundo épico exclui a 
aventura, nesse sentido próprio: os heróis da epopeia percorrem uma série variegada de aventuras, mas que vão superá-las, tanto interna quanto externamente, isso nunca é posto em dúvida" (p.91). No jogo, no entanto, não há superação de conflitos; ao invés disso, temos um desfecho que denota mais perguntas do que respostas: a atitude de Joel foi ética? Ellie era mesmo a única esperança de cura para a humanidade? Há de fato a chance de reconstituir a sociedade e resgatar a relação orgânica entre os humanos?

\section{Considerações Finais}

Mesmo em contato com uma mídia relativamente nova, pois estamos falando de pouco mais de 50 anos de idade, ainda é possível reconhecer nela elementos que fundamentaram o desenvolvimento das narrativas em diferentes épocas. Afinal, mesmo passando por transformações, o ser humano ainda se vê frente a conflitos de certa forma atemporais, em sua maioria pautados nas relações entre homem e sociedade. Tais conflitos são, com grande frequência, personificados por um herói que deve enfrentar obstáculos a fim de encontrar uma solução nem sempre feliz para suas aflições. Provavelmente, enquanto existir sociedade, tais conflitos estarão lá.

Em vários momentos da narrativa, o jogador sofre junto com Joel as consequências dos eventos do jogo: o choque de perder a filha e a incapacidade de salvá-la, os conflitos com os infectados e os não infectados, a falta de contato com o mundo externo, os momentos de nostalgia ao longo de sua jornada e, finalmente, o medo de perder Ellie (o que significaria perder sua filha novamente). Todos esses eventos colaboram para proporcionar ao jogador uma experiência intensa e impactante e que, de certa maneira, pode se igualar à experiência vivida com a leitura de uma obra impressa.

O desfecho do jogo é tanto um momento de tensão quanto de traição para o jogador. Não há como não se indignar com a possibilidade da morte de Ellie e com a mentira de Joel. Os dois eventos colocam o jogador em posição extrema. Somos forçados a aceitar as atitudes de Joel mesmo não concordando com elas; mesmo reconhecendo a forte relação paternal entre as personagens, é custoso aceitar que o herói não cumpriu sua tarefa e modificou o curso dos eventos por um interesse individual.

A estrutura dos jogos eletrônicos tem cada vez mais se provado próxima dos textos clássicos, seja pelos temas selecionados, seja pela estrutura da narrativa ou até mesmo pelas referências apresentadas. No entanto, a figura do herói nem sempre refletirá aquela dos 
textos clássicos, pois o mundo moderno já não mais oferece uma sociedade unificada e o indivíduo não se vê mais cercado de certezas.

Em seu texto acerca do cânone literário, Alvelar (2009) nos alerta para vários perigos ao tentarmos classificar as obras literárias a partir de uma ótica trans-histórica, sem considerar mudanças sociais, as diferentes visões dos escritores e os usos da literatura para a sociedade. Mesmo sendo esse um texto acerca do valor estético dos textos literários, é possível estender suas ideias sobre a valoração da literatura para as relações entre esta e as novas mídias:

\begin{abstract}
A história da profissionalização do escritor e das suas relações com a imprensa e com o mercado ainda nos oferece vastas zonas de pesquisa ainda não realizada. Para além do lamento de que a internet é responsável por uma queda na qualidade e na frequência da leitura das novas gerações (...) uma série de novos escritores faz uso das tecnologias de publicação online para circular seus textos e manufaturar concepções emergentes de valor estético. $\mathrm{O}$ postulado da contingência essencial do valor só abre um espaço de relevância ainda maior para essas pesquisas. (ALVELAR, 2009,p. 146)
\end{abstract}

Fica estabelecida a nosso ver, então, a relevância das pesquisas que englobam a relação entre as novas mídias e a Literatura tal como a conhecemos; no entanto, é crucial que tal exercício investigativo seja livre da contingência do valor estético. Sendo assim, concordamos com Seraphine quando diz que:

Contudo, talvez nós devêssemos ter como objetivo contar uma história - seja ela linear ou não - com o uso da interatividade como uma ferramenta semântica. Em outras palavras, nós não deveríamos criar histórias interativas, mas sim histórias contadas através da interatividade. (SERAPHINE, 2014, loc. 88. Trad. nossa) ${ }^{9}$

A questão central, portanto, não é estabelecer a superioridade ou inferioridade de um determinado suporte em detrimento de outro. Acima de tudo, está o interesse pelo

\footnotetext{
${ }^{9}$ Yet perhaps should we simply aim at telling a story - may it be linear or interactive - with interactivity as a semantic tool. In other words, we should not try to create interactive stories, but rather stories interactively told. (SERAPHINE, 2014, loc. 88)
} 
universo de possibilidades que cada um apresenta e pela experiência que cada um deles nos proporciona, ressaltando a sua relevância para a sociedade e reconhecendo seu caráter transformador na ampliação dos horizontes do sujeito que nela está inserido. Na colaboração para a migração, a mutação e o florescimento das narrativas é que buscamos nas novas mídias uma comunhão.

\section{Referências}

ALMEIDA, M. P. Discurso sobre o poema heroico. In: REEL - Revista Eletrônica de Estudos Literários, Vitória. a. 2, n. 2, 2006. Disponível em: http://periodicos.ufes.br/reel/article/view/3429/2684. Acesso: 20/08/2016.

ALVELAR, I. Cânone literário e valor estético: notas sobre um debate do nosso tempo. In: Revista Brasileira de Literatura Comparada, Edição n. 15, Niterói: 2009. p. 113 - 150.

AMORIM, L. M.. Tradução e adaptação: encruzilhadas da textualidade em Alice no País das Maravilhas, de Lewis Carroll, e Kim, de Rudyard Kipling. São Paulo: Editora UNESP, 2005.

ARISTÓTELES. Poética. Trad. Eudoro de Souza. São Paulo: Ars Poetica, 1992.

CARVALHAL, T. F. Literatura comparada: A estratégia interdisciplinar. In: Revista Brasileira de Literatura Comparada. Edição n. 1. Niterói: 1991. p. 9 - 21.

DONKEY KONG. Nintendo Research \& Development: 1981.

HEAVY RAIN. Quantic Dream: Sony Computer Entertainment, 2010.

HUTCHEON, L. Uma teoria da adaptação. Trad. André Cechinel. Florianópolis: Editora UFSC, 2011.

LUKÁCS, G. A teoria do romance. Trad. José Marcos Mariani de Macedo. São Paulo: Duas Cidades: Editora 34, 2000.

MANGAN, M. A preface to Shakespeare's comedies: 1594-1603. New York: Routledge, 2013.

SAMOYAULT, T. A intertextualidade. Trad. Sandra Nitrini. São Paulo: Aderaldo \& Rothschild, 2008.

SPALDING, A. Sherlock Holmes: The awakened (Frogwares), Sherlock Holmes (Sir Arthur Conan Doyle), Cthulu Mythos (H.P. Lovecraft). In: THOMPSON, Michael (ed). Literature and Video Games. Kindle edition, 2012. 
SERAPHINE, F. The intrinsic semiotics of video-games. In: Search of games' narrative potential. Amazon: Kindle edition, 2014.

SUCKLING, M. \& WALTON, M. Video game writing: from macro to micro. Kindle: Mercury Learning \& Information, 2012.

THE LAST OF US. Naughty Dog: Sony Computer Entertainment: 2013.

\title{
The heritage of epic and tragic poems in videogames and a short analysis of the videogame The Last of $U$ s
}

\begin{abstract}
Considering the social transformations, especially the development of new medias, which have narrative potential, this paper aims at reflecting upon the exchange between these new medias, particularly the video game, and Literature. Besides, it highlights the intertextual connection between different medias that frequently explore widely known narratives through their reconfiguration. Taking into consideration the aspects aforementioned, it becomes clear that the themes explored in videogames are closely connected to classical texts, especially epic poems and tragedies. Not only they explore similar themes but they also share similarities within their structure. It will also present an analysis of the game The Last of Us in order to point out which elements are recursive in both epic poems and the game chosen for the article. It will pay special attention to the role of the hero in the development of the narrative.
\end{abstract}

Key words: Literature. Videogame. Intertextuality. Epic poems and tragedies. The Last of Us.

Recebido em: 29 de agosto de 2016.

Aprovado em: 03 de janeiro de 2017. 